\title{
The Gas-Phase H/D Exchange Mechanism of Protonated Amino Acids
}

\author{
Marko Rožman \\ Laboratory for Chemical Kinetics and Atmospheric Chemistry, Ruđer Bošković Institute, Zagreb, Croatia
}

A mass spectrometry and Density Functional Theory study of gas-phase H/D exchange in protonated Ala, Cys, Ile, Leu, Met, and Val is reported. Site-specific rate constants were determined and results identify the $\alpha$-amino group as the protonation site. Lack of exchange on the Cys thiol group is explained by the absence of strong intramolecular hydrogen bonding within the reaction complex. In aliphatic amino acids the presence of a methyl group at the $\beta-C$ atom was found to lower the site-specific H/D exchange rate for amino hydrogens. Study of the exchange mechanism showed that isotopic exchange occurs in two independent reactions: in one, only the carboxylic hydrogen is exchanged and in the other, both carboxylic and amino group hydrogens exchange. The proposed reaction mechanisms, calculated structures of various species, and a number of structural findings are consistent with experimental data. (J Am Soc Mass Spectrom 2005, 16, 1846-1852) (c) 2005 American Society for Mass Spectrometry

$\mathrm{O}$ ne of the mass spectrometry techniques capable of going beyond primary structural investigations is gas-phase H/D exchange. Although gas-phase $\mathrm{H} / \mathrm{D}$ exchange reactions are widely used [1-23], only the reaction mechanism with $\mathrm{ND}_{3}$ as the deuterating agent has been studied in detail [24]. Several studies discussed simplified mechanisms of $\mathrm{H} / \mathrm{D}$ exchange reactions with $\mathrm{CH}_{3} \mathrm{OD}$ and $\mathrm{D}_{2} \mathrm{O}$ as deuterium donors. Gur et al. [7] suggested that $H / D$ exchange in dipeptides occurs through stabilization of a reaction complex [dipeptide $-\mathrm{H}$ ] $-\mathrm{HD}_{2} \mathrm{O}^{+}$. Green and coworkers [2] proposed a schematic mechanism in which $\mathrm{H} / \mathrm{D}$ exchange begins with formation of a hydrogen bonded complex between a protonated amino acid and a deuteration reagent, Scheme 1.

Campbell et al. [6] proposed several H/D exchange mechanisms for different sites of polypeptide molecules. They studied exchange mechanisms by PM3 and AM1 semiempirical calculations where some reaction intermediates were determined and then fitted into the proposed reaction coordinate. For protonated glycine they reported only one exchange, which they assigned to the carboxylic hydrogen. Also, they suggested that carboxylic hydrogen exchange proceeds by either a "salt-bridge" or "flip-flop" mechanism, Scheme 2.

Because of the complex structure of biomolecules, it is difficult to unambiguously interpret $\mathrm{H} / \mathrm{D}$ exchange results. Therefore, to interpret them correctly, it is important to consider the interaction of the biomolecule with a deuterium donor, the structure of the reaction complex, and the mechanism of isotopic exchange. This

Published online September 29, 2005

Address reprint requests to Dr. M. Rožman, Laboratory for Chemical Kinetics and Atmospheric Chemistry, Ruđer Bošković Institute, Bijenička 54, HR-10002 Zagreb, Croatia. E-mail: marko@irb.hr motivated us to investigate thoroughly the gas-phase $\mathrm{H} / \mathrm{D}$ exchange reactions of protonated amino acids, Ala, Cys, Ile, Leu, Met, and Val with $\mathrm{D}_{2} \mathrm{O}$ and $\mathrm{CD}_{3} \mathrm{OD}$. Here, a mass spectrometric investigation of hydrogen bonds in the reaction complex and the effects of the aliphatic side chains, accompanied by the corresponding density functional theory (DFT) description of the dynamic pathway for $\mathrm{H} / \mathrm{D}$ exchange between $\mathrm{AlaH}^{+}$ and $\mathrm{D}_{2} \mathrm{O}$, are given and discussed.

\section{Experimental}

All amino acids (Ala, Cys, Ile, Leu, Met, and Val) and amino acid methyl esters (AlaOMe, LeuOMe, and Val$\mathrm{OMe}$ ) were obtained from Fluka (Buchs, Switzerland). The deuteration reagent $\mathrm{D}_{2} \mathrm{O}(99.8 \%)$ was from Aldrich (Milwaukee, WI) and $\mathrm{CD}_{3} \mathrm{OD}(99.8 \%)$ was from Cambridge Isotope Laboratories (Andover, MA). MALDI samples were prepared with a standard dried-droplet procedure using 2,5-dihydroxybenzoic acid (DHB) as the matrix. Two consecutive $337 \mathrm{~nm}$ laser pulses from a nitrogen laser (VSL 337 NSD, LSI Laser Science, Newton, MA) were used to produce gas-phase samples. The $\mathrm{H} / \mathrm{D}$ exchange experiments were performed in a $3 \mathrm{~T}$ Fourier transform ion cyclotron resonance (FTICR)<smiles>[R]OPOC(=O)C([R2])[NH3+]</smiles>

Scheme 1 
<smiles>[2H]OB(OC[C@@H](O)C[NH3+])OC(=O)C[NH3+]</smiles>
salt-bridge mechanism

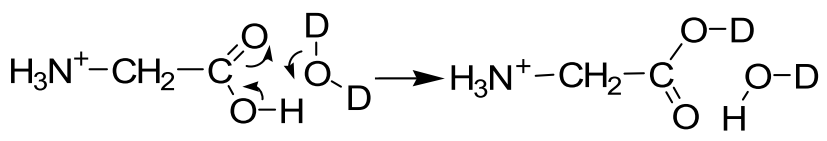

flip-flopmechanism

Scheme 2

mass spectrometer (Extrel FTMS 2001, Madison, WI). The stabilized reagent gas pressure used in the exchange experiments was $2.67-1.33 \cdot 10^{-5} \mathrm{~Pa}$ at an ambient temperature of $300 \mathrm{~K}$. The pressure measurement, $\mathrm{H} / \mathrm{D}$ exchange experiments and determination of the site-specific reaction rate constants were performed by using the procedure described previously [18]. Repetitive H/D exchange experiments indicate a relative standard deviation of up to $30 \%$ for the reported site-specific rate constants.

DFT calculations were performed using the Gaussian 03 [25] program package. Although initial checks of the potential energy surface were done using a B3LYP functional with $6-31 G^{*}$ basis set, attempts to identify reaction intermediate HD3 were unsuccessful. On the other hand, optimization at the B3LYP/6-311++ $G^{* *}$ level successfully identified minimum HD3 so all further calculations were done directly with the $6-311++\mathrm{G}^{* *}$ basis set. Each stationary point (minimum on the potential energy surface) was tested by a harmonic vibrational analysis. The structures of the transition states were obtained by QST2 and QST3 optimization procedures. Transition-state structures were verified by harmonic frequency analysis and by intrinsic reaction coordinate (IRC) analysis for the reaction pathways. IRC analysis of the reaction pathway from transition-state TS-HD23 to reaction intermediates HD2 and HD3 was unsuccessful. The same analysis (only for TS-HD23) was successfully carried out using the GAMESS [26] software package. Energies of reactants and reaction intermediates were not corrected for zero point energies. The basis set superposition error (BSSE) counterpoise corrected potential energy profile for the "flip-flop" mechanism was calculated and it was found that relative energies of conformers vary up to 2
$\mathrm{kJ} \mathrm{mol}^{-1}$, so it was assumed that relative energies of studied structures are independent of BSSE. To test if changes of the density functionals alter structures and (or) potential energy surface of the studied reactions, the "flip-flop" reaction mechanism was calculated at the B3PW91/6-311 $++G^{* *}$ level and found to be in good agreement with B3LYP results (relative energies changed by $3 \mathrm{~kJ} \mathrm{~mol}^{-1}$ ).

\section{Results and Discussion}

\section{H/D Exchange of Protonated Aliphatic Amino Acids}

Compounds selected for this study were: (1) amino acids with aliphatic side chains, e.g., Ala, Ile, Leu, and Val. They were selected because their side chains do not contain active sites that can exchange hydrogen(s) or participate in formation of additional hydrogen bonds within the reaction complex. (2) amino acids Cys and Met with side chains containing sulfur atoms. The absence of gas-phase H/D exchange in reactions of protonated amino acids with $\mathrm{D}_{2} \mathrm{~S}$ suggests weak hydrogen bonding within the protonated amino acid- $\mathrm{D}_{2} \mathrm{~S}$ complex [18]. Stabilization through formation of a weakly hydrogen bonded reaction complex with $\mathrm{D}_{2} \mathrm{~S}$ was not sufficient to overcome the reaction barrier for isotopic exchange. Thus, it was assumed that the $\mathrm{CysH}^{+}$thiol group hydrogen would also not be exchanged.

Because all selected amino acids have similar proton affinities [27] and consequently, similar proton affinity differences between amino acid and deuterium donor, one can also expect similar reactivity, i.e., similar H/D reaction rates.

Gas-phase H/D exchange of protonated amino acids and protonated amino acid methyl esters with $\mathrm{CD}_{3} \mathrm{OD}$ and $\mathrm{D}_{2} \mathrm{O}$ was observed. The studied amino acids exchanged all labile hydrogens but no exchange of $\mathrm{CysH}^{+}$ thiol group hydrogen was observed, consistent with the assumption above. The reaction data were analyzed and site-specific reaction rate constants were determined (Table 1 and Table 2).

Kinetic results show one fast and three equivalent slow exchanging hydrogens for all amino acids. Results for protonated amino acid methyl esters show three equivalent exchanging hydrogens. By comparison with protonated amino acids, the single nonequivalent fast

Table 1. Site-specific H/D exchange rate constants $\left(\times 10^{-11} \mathrm{~cm}^{3} \mathrm{~s}^{-1}\right.$ molecules $\left.{ }^{-1}\right)$ for reaction of the studied protonated amino acids with $\mathrm{CD}_{3} \mathrm{OD}$ and $\mathrm{D}_{2} \mathrm{O}$

\begin{tabular}{|c|c|c|c|c|c|c|c|c|c|c|c|c|}
\hline \multirow{2}{*}{$\begin{array}{l}\text { Amino Acid } \\
\text { Deuterium Donor }\end{array}$} & \multicolumn{2}{|c|}{$\mathrm{AlaH}^{+}$} & \multicolumn{2}{|c|}{$\mathrm{CysH}^{+}$} & \multicolumn{2}{|c|}{$\mathrm{IleH}^{+}$} & \multicolumn{2}{|c|}{$\mathrm{LeuH}^{+}$} & \multicolumn{2}{|c|}{$\mathrm{MetH}^{+}$} & \multicolumn{2}{|c|}{$\mathrm{ValH}^{+}$} \\
\hline & $\mathrm{CD}_{3} \mathrm{OD}$ & $\mathrm{D}_{2} \mathrm{O}$ & $\mathrm{CD}_{3} \mathrm{OD}$ & $\mathrm{D}_{2} \mathrm{O}$ & $\mathrm{CD}_{3} \mathrm{OD}$ & $\mathrm{D}_{2} \mathrm{O}$ & $\mathrm{CD}_{3} \mathrm{OD}$ & $\mathrm{D}_{2} \mathrm{O}$ & $\mathrm{CD}_{3} \mathrm{OD}$ & $\mathrm{D}_{2} \mathrm{O}$ & $\mathrm{CD}_{3} \mathrm{OD}$ & $\mathrm{D}_{2} \mathrm{O}$ \\
\hline$k_{1}$ & 127 & 4.44 & 106 & 5.16 & 89.2 & 1.99 & 87.4 & 2.84 & 78.2 & 4.05 & 78.2 & 2.12 \\
\hline$k_{2}$ & 1.22 & 0.52 & 1.38 & 0.47 & 0.58 & 0.39 & 1.15 & 0.44 & 1.01 & 0.65 & 0.74 & 0.31 \\
\hline$k_{3}$ & 1.22 & 0.52 & 1.38 & 0.47 & 0.58 & 0.39 & 1.15 & 0.44 & 1.01 & 0.65 & 0.74 & 0.31 \\
\hline$k_{4}$ & 1.22 & 0.52 & 1.38 & 0.47 & 0.58 & 0.39 & 1.15 & 0.44 & 1.01 & 0.65 & 0.74 & 0.31 \\
\hline
\end{tabular}


Table 2. Site-specific H/D exchange rate constants $\left(\times 10^{-11}\right.$ $\mathrm{cm}^{3} \mathrm{~s}^{-1}$ molecules ${ }^{-1}$ ) for reaction of the studied protonated amino acids methyl esters with $\mathrm{CD}_{3} \mathrm{OD}$ and $\mathrm{D}_{2} \mathrm{O}$

\begin{tabular}{|c|c|c|c|c|c|c|}
\hline \multirow{2}{*}{$\begin{array}{l}\text { Methyl ester } \\
\text { Deuterium } \\
\text { Donor }\end{array}$} & \multicolumn{2}{|c|}{$\mathrm{AlaOMeH}^{+}$} & \multicolumn{2}{|c|}{$\mathrm{LeuOMeH}^{+}$} & \multicolumn{2}{|c|}{$\mathrm{ValOMeH}^{+}$} \\
\hline & $\mathrm{CD}_{3} \mathrm{OD}$ & $\mathrm{D}_{2} \mathrm{O}$ & $\mathrm{CD}_{3} \mathrm{OD}$ & $\mathrm{D}_{2} \mathrm{O}$ & $\mathrm{CD}_{3} \mathrm{OD}$ & $\mathrm{D}_{2} \mathrm{O}$ \\
\hline$k_{1}$ & 1.61 & 0.62 & 0.97 & 0.6 & 0.61 & 0.25 \\
\hline$k_{2}$ & 1.61 & 0.62 & 0.97 & 0.6 & 0.61 & 0.25 \\
\hline$k_{3}$ & 1.61 & 0.62 & 0.97 & 0.6 & 0.61 & 0.25 \\
\hline
\end{tabular}

exchanging site can be attributed to the carboxylic group. Therefore, three equivalent exchanging sites strongly imply that the amino group is the protonation site, in agreement with theoretical results [28]. Sitespecific kinetic studies $[9,13]$ done on a similar system (glycine) give us an opportunity to compare results. The observation of one fast and three equivalent slow exchanging hydrogens is the same in all studies. Experimental values of the rate constants are consistent with those obtained by Green and Lebrilla [9], while there is some inconsistency in the magnitude (arising mainly from the pressure measurement) with those obtained by He and Marshall [13].

The constants show a surprising decrease in amino group hydrogen exchange rates for $\mathrm{IleH}^{+}$and $\mathrm{ValH}^{+}$. Because only $\mathrm{IleH}^{+}$and $\mathrm{ValH}^{+}$have a methyl group at their $\beta$-C atoms, a possible steric effect of this methyl group on the most stable conformations of $\mathrm{IleH}^{+}$and $\mathrm{LueH}^{+}$was analyzed theoretically.

Eight initial structures of both amino acids were built from the structures protonated at the nitrogen with a hydrogen bond between the $-\mathrm{NH}_{3}{ }^{+}$group and the carbonyl oxygen. Aliphatic side chains in both amino acids were placed in various positions with steric strain taken into consideration. Obtained structures were then fully optimized at the B3LYP/6-31G* level to yield five stable structures. The three energetically lowest conformers were subsequently fully optimized at the B3LYP / 6-311 $++G^{* *}$ level to obtain their relative stabilities. The lowest energy conformations of $\mathrm{IleH}^{+}$and LeuH ${ }^{+}$are shown in Figure 1. The corresponding B3LYP $/ 6-311++G^{* *}$ energies and relative stabilities $(\Delta)$ are listed in Table 3.

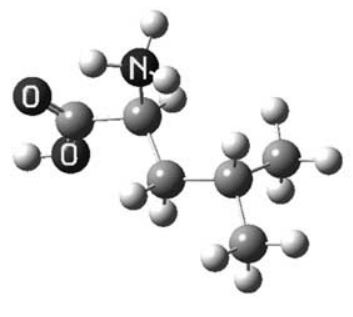

$\operatorname{LeuH}^{+}(1)$

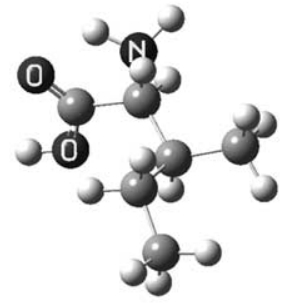

$\mathrm{IleH}^{+}(1)$
Figure 1. Optimized structures of $\operatorname{IleH}^{+}(1)$ and $\mathrm{LeuH}^{+}(1)$ obtained at the B3LYP/6-311++ $\mathrm{G}^{* *}$ level.
Table 3. The B3LYP/6-311++ $\mathrm{G}^{* *}$ energies (in $E_{\mathrm{h}}$ ) and relative stabilities (in $\mathrm{kJ} \mathrm{mol}^{-1}$ ) of $\mathrm{IleH}^{+}$and $\mathrm{LeuH}^{+}$conformers

\begin{tabular}{llllll}
\hline & \multicolumn{2}{c}{ B3LYP/6-31G* } & & \multicolumn{2}{c}{ B3LYP/6-311++G** } \\
\cline { 2 - 3 } \cline { 6 - 6 } Structure & \multicolumn{1}{c}{$E$} & $\Delta$ & & \multicolumn{1}{c}{$E$} & \multicolumn{1}{c}{$\Delta$} \\
\hline \hline $\operatorname{LeuH}^{+}(1)$ & -442.049133 & 0 & & -442.189218 & 0 \\
$\operatorname{LeuH}^{+}(2)$ & -442.048184 & 2.5 & & -442.188273 & 2.5 \\
$\mathrm{LeuH}^{+}(3)$ & -442.0476264 & 3.9 & & -442.187728 & 3.9 \\
$\mathrm{IeH}^{+}(1)$ & -442.048556 & 0.0 & & -442.188508 & 0 \\
$\mathrm{IleH}^{+}(2)$ & -442.046757 & 4.7 & & -442.186391 & 5.6 \\
$\mathrm{IleH}^{+}(3)$ & -442.046769 & 4.7 & & -442.18625 & 5.9 \\
\hline
\end{tabular}

Although an increase of the basis set does not alter significantly the relative energies of the conformers, to get a more accurate description all final conformations and energetics were obtained with the $6-311++G^{* *}$ basis set. The lowest energy conformation of $\mathrm{LeuH}^{+}$is a structure $\mathrm{LeuH}^{+}(1)$ in which methyl groups at the $\gamma$-C atom are oriented away from the amino and carboxylic groups and, therefore, do not pose steric hindrance. However, $\mathrm{IleH}^{+}(1)$, where the methyl and ethyl groups of the $\beta$-C atom are closer to the amino and carboxylic groups, appears to be energetically more stable, Table 4 .

Based on these structural data, we presume that a methyl group on the $\beta$-C atom of an aliphatic amino acid poses significant steric hindrance for the amino and carboxylic groups, which probably causes the decrease in the amino group hydrogen exchange rate. However, such an assumption needs confirmation through a detailed analysis of the $\mathrm{H} / \mathrm{D}$ exchange mechanism, vide infra.

\section{The H/D Exchange Mechanism}

For practical reasons (computational time and resources), the computational study of $\mathrm{H} / \mathrm{D}$ exchange in protonated aliphatic amino acids was carried out for the smallest molecules used in the experiments: $\mathrm{AlaH}^{+}$and $\mathrm{D}_{2} \mathrm{O} . \mathrm{AlaH}^{+}$was used as a model compound for all amino acids except for those in which the side-chain group partakes in the $\mathrm{H} / \mathrm{D}$ exchange process. $\mathrm{D}_{2} \mathrm{O}$ and $\mathrm{CD}_{3} \mathrm{OD}$ exhibit similar reactivities, and both participate in a single deuterium exchange per reactive encounter $[3,6]$, so the mechanism may apply for both. In the calculations, the $\mathrm{D}_{2} \mathrm{O}$ molecule was simulated by $\mathrm{H}_{2} \mathrm{O}$.

Interaction of MALDI generated $\mathrm{AlaH}^{+}$(expected to be in the most stable conformation [29] and $\mathrm{D}_{2} \mathrm{O}$ begins

Table 4. Distances (in $\AA$ ) between bolded atoms in the $\mathrm{IleH}^{+}$ and $\mathrm{LeuH}^{+}$calculated at the B3LYP/6-311 $++\mathrm{G}^{* *}$ level of theory

\begin{tabular}{lcc}
\hline & IleH $^{+}(1)$ & LeuH $^{+}(1)$ \\
\hline \hline $\mathrm{CH}_{3} \ldots \mathrm{NH}_{3}$ & 3.08 & 4.47 \\
$\mathrm{CH}_{3} \ldots \mathrm{CO}$ & 4.84 & 5.82 \\
$\mathrm{CH}_{3} \ldots \mathrm{COH}$ & 4.34 & 5.39 \\
$\mathrm{CH}_{3} \mathrm{CH}_{2} \ldots \mathrm{NH}_{3}$ & 3.07 & - \\
$\mathrm{CH}_{3} \mathrm{CH}_{2} \ldots \mathrm{CO}$ & 3.78 & - \\
$\mathrm{CH}_{3} \mathrm{CH}_{2} \ldots \mathrm{COH}$ & 3.51 & - \\
\hline
\end{tabular}


20

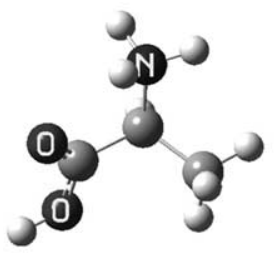

HD1

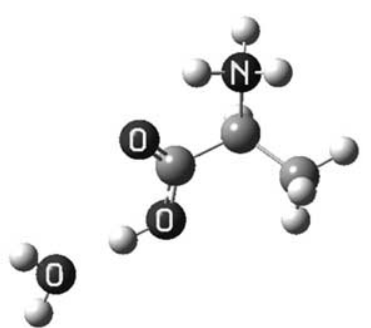

HDC1

Figure 2. Minima HD1 and HDC1, results of B3LYP $6-311++\mathrm{G}^{* *}$ optimization.

with collisions from various directions. Molecular dynamic simulations of interactions in similar systems showed that, depending on the direction, the deuterium donor within a few ps interval stabilizes near the active/preferred site $[12,23]$. In $\mathrm{AlaH}^{+}$the active sites are the carboxylic and amino groups. Various reaction complexes were generated in such a way that the $\mathrm{D}_{2} \mathrm{O}$ molecule was placed in the proximity of the $\mathrm{AlaH}^{+}$ active sites. The complexes were then optimized at the B3LYP $/ 6-311++G^{* *}$ level (Figure 2). For the carboxylic site, five initial structures gave minimum HDC1, while for the amino site, six initial structures gave three

minima (in each minimum molecule $\mathrm{D}_{2} \mathrm{O}$ was oriented toward one of the three amino hydrogens, as in HD1). HD1 is a global minimum, however, the energy differences between three amino site minima are very small, less than $2.5 \mathrm{kJmol}^{-1}$. Therefore, it is conceivable that during interaction of $\mathrm{AlaH}^{+}$and $\mathrm{D}_{2} \mathrm{O}, \mathrm{D}_{2} \mathrm{O}$ oscillates around the amino group and before isotopic exchange stabilizes into position HD1, Figure 2.

The minimum HD1 is $6.1 \mathrm{~kJ} \mathrm{~mol}^{-1}$ more stable than HDC1 and therefore we first analyzed the reaction mechanism that originates from HD1. The B3LYP/6$311++G^{* *}$ potential energy profile together with optimized structures for the $\mathrm{H} / \mathrm{D}$ exchange of $\mathrm{AlaH}^{+}$with $\mathrm{D}_{2} \mathrm{O}$ is shown in Figure 3.

Before describing the reaction mechanism, it is interesting to compare the hydrogen bonded complex proposed by Gard et al. [2] (Scheme 1) with the starting complex HD1. In HD1, the $\mathrm{D}_{2} \mathrm{O}$ molecule is situated $(3.14 \AA)$ away from the carbonyl oxygen without formation of a hydrogen bond between them. Attempts to stabilize the reaction minimum by moving $\mathrm{D}_{2} \mathrm{O}$ closer to the oxygen were unsuccessful. A slight move of $\mathrm{D}_{2} \mathrm{O}$ towards the carbonyl oxygen is a result of hydroxyl group rotation by $180^{\circ}$ around the $\mathrm{C}-\mathrm{O}$ bond over transition-state TS-HD12 into HD2. Formation of reaction intermediate HD2 is a prerequisite for the start of isotopic exchange which leads to concerted hydrogen/ deuterium transfer from HD2 in the transition-state TS-HD23. Here one of the $-\mathrm{NH}_{3}{ }^{+}$hydrogens is trans-

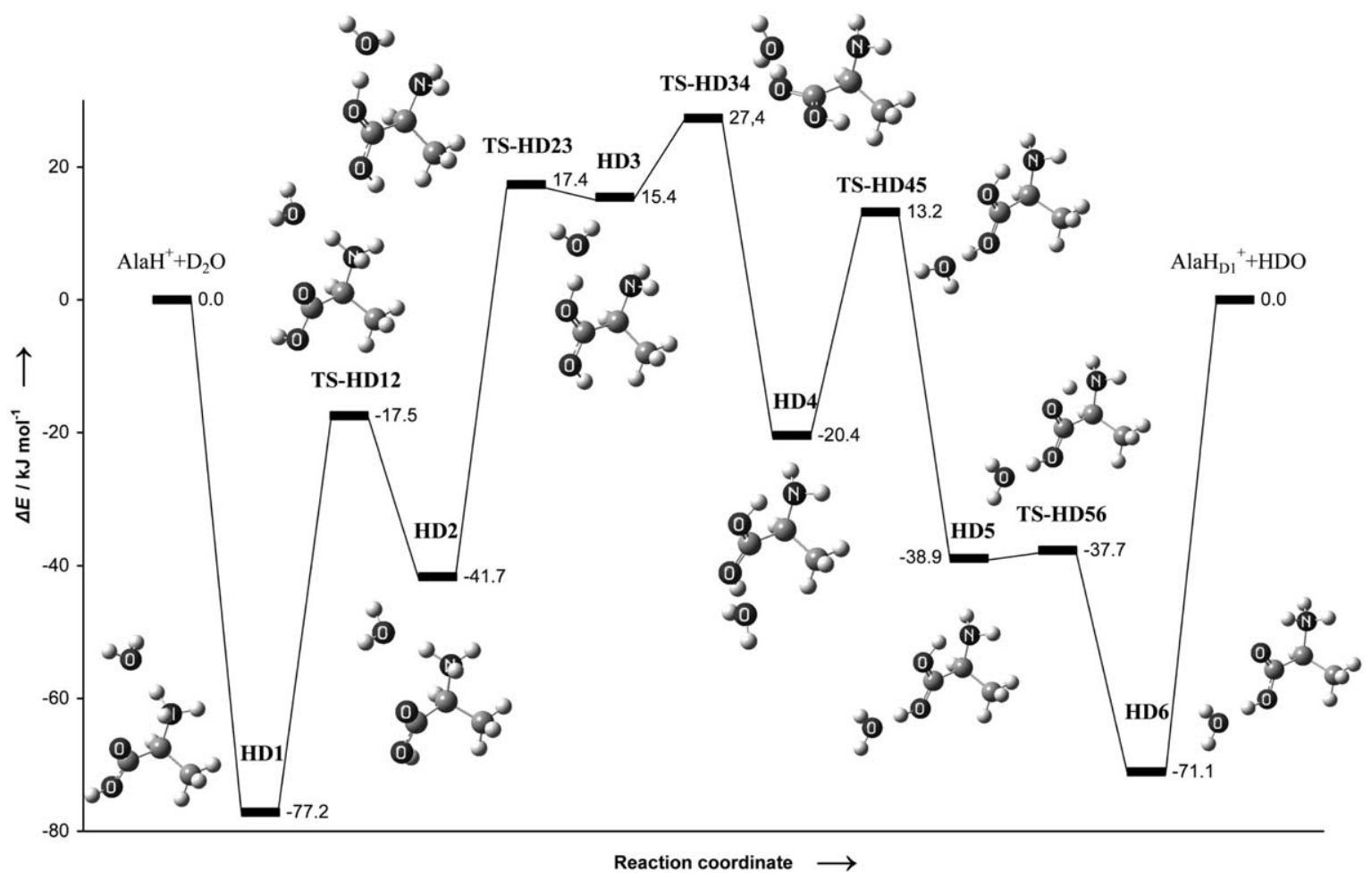

Figure 3. Scheme of the potential energy profile for $\mathrm{H} / \mathrm{D}$ exchange in $\mathrm{AlaH}^{+}$with $\mathrm{D}_{2} \mathrm{O}$. The relative energies and optimized structures were calculated at the B3LYP $/ 6-311++G^{* *}$ level of theory. Also see Table 1 in the Appendix section. 


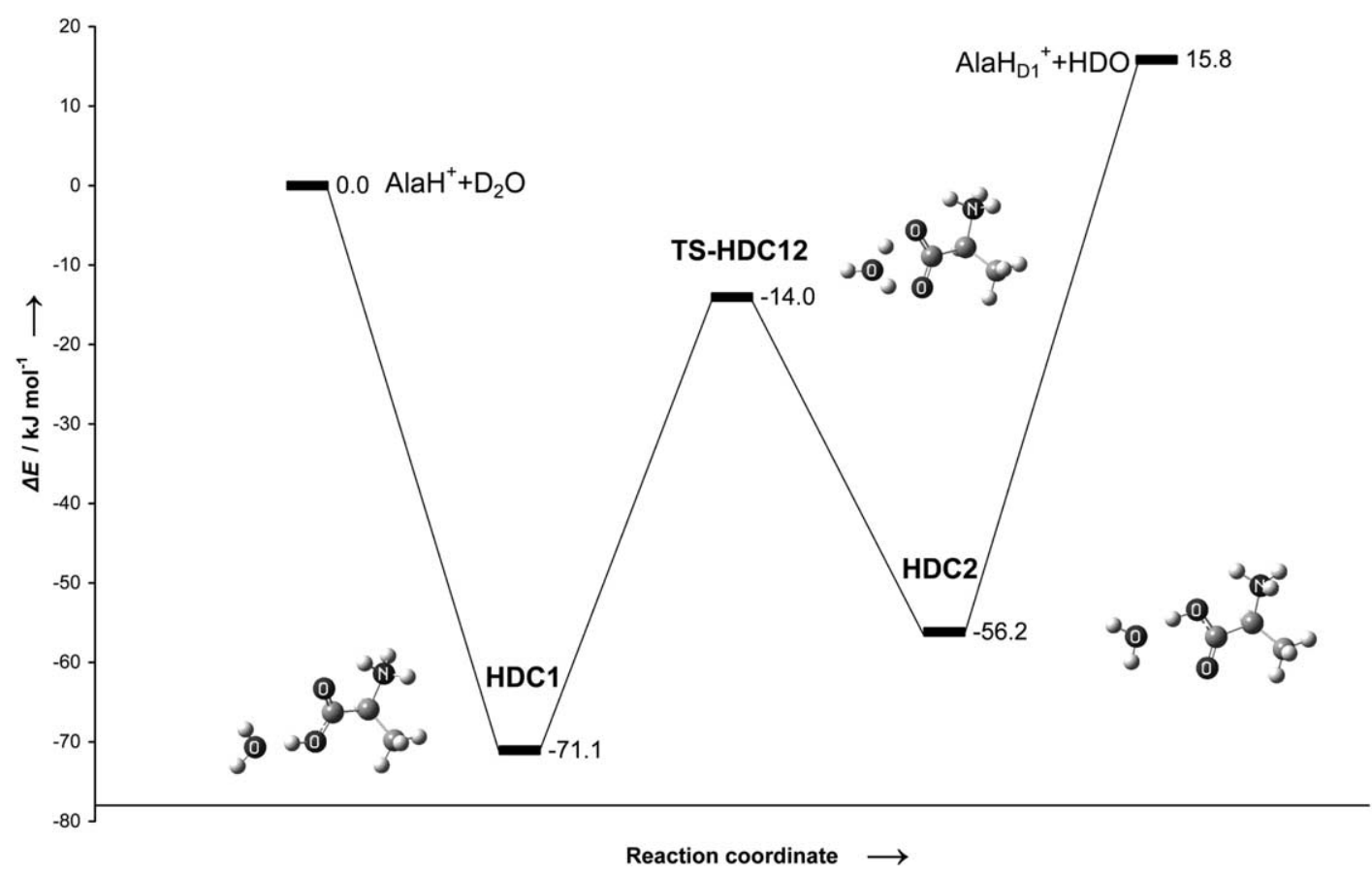

Figure 4. Schematic representation of the potential energy profile for the $\mathrm{H} / \mathrm{D}$ exchange of the $\mathrm{AlaH}^{+}$carboxylic hydrogen with $\mathrm{D}_{2} \mathrm{O}$. The relative energies and optimized structures were calculated at the B3LYP/6-311++ $\mathrm{G}^{* *}$ level of theory. Also see Table 2 in the Appendix section.

ferred to $\mathrm{D}_{2} \mathrm{O}$ while, simultaneously, one of the deuteriums moves to the carbonyl oxygen. The imaginary vibrational frequency $\left(48.61 \mathrm{i} \mathrm{cm}{ }^{-1}\right)$ of transition-state TS-HD23 corresponds to alternate swinging of HDO towards the $-\mathrm{NH}_{2}$ or $-\mathrm{COD}(\mathrm{OH})$ group of "enolic" $\mathrm{AlaH}^{+}$. After the concerted H/D transfer, rotation of the $-\mathrm{COD}(\mathrm{OH})$ group around the $\mathrm{C}-\mathrm{C} \alpha$ axis occurs from HD3 to HD4. Simultaneously, the HDO molecule becomes perpendicular to the $-\mathrm{COD}(\mathrm{OH})$ group plane. The corresponding transition-state TS-HD34 is associated with the energetically highest barrier. The next reaction step is a concerted exothermic rotation of the -OD group and HDO molecule through the transitionstate TS-HD45 leading to reaction intermediate HD5. Finally, reaction intermediate HD6 with a protonated $\alpha$-amino group is formed by proton transfer from $-\mathrm{DOCOH}$ to the $-\mathrm{NH}_{2}$ group from reaction intermediate HD5.

The reaction energy profile (Figure 3) shows that the energy gain from initial HD1 reaction complex formation is not sufficient to overcome the reaction barrier(s) and, consequently, low reaction rates will result. Furthermore, this mechanism gives equal exchange rates for carboxylic and amino hydrogens while experimental results $[9,13,18]$ suggest that a carboxylic hydrogen is exchanged 10 to 100 times faster than one of the amino group.

The above findings suggest existence of an additional mechanism for the carboxylic hydrogen exchange. Campell et al. [6] already proposed the "flipflop" and "salt-bridge" mechanisms for exchange. Present calculations suggest that $H / D$ exchange at the carboxylic oxygen via proton transfer by formation of a "hydronium" cation is very unfavorable, and our attempts to find this mechanism were unsuccessful. On the other hand, the "flip-flop" mechanism which starts from minimum HDC1 appears to be essentially barrierless, Figure 4.

The H/D exchange process is described through the transition-state TS-HDC12, which represents concerted double hydrogen/deuterium transfer. The energy barrier towards transition-state TS-HDC12 is overcome by stabilization of the intermediate HDC1 resulting in fast exchange of the carboxylic hydrogen, consistent with experimental results. Of course, after or during dissociation of $\mathbf{H D C} 2, \mathrm{AlaH}_{\mathrm{D} 1}{ }^{+}$returns (not shown in Figure 4) to its most stable conformation, which results in needed product stabilization.

It follows that $\mathrm{H} / \mathrm{D}$ exchange of protonated aliphatic amino acids is the result of two reactions: in the faster and energetically more favorable first reaction, only the carboxylic hydrogen is exchanged while in the second reaction, both carboxylic and amino group hydrogens are exchanged. As experimental support for this model we consider the following: (1) fast exchange of the hydroxylic hydrogen, which is essentially thermo neutral and whose exchange rates are 10 to 100 times faster than those for amino group hydrogens [13, 18], and (2) decrease of the amino group hydrogen exchange rates in $\mathrm{IleH}^{+}$and $\mathrm{ValH}^{+}$because their additional methyl group on $\beta-\mathrm{C}$ atoms hinders the $-\mathrm{COD}(\mathrm{OH})$ group rotation around the $\mathrm{C}-\mathrm{C} \alpha$ axis and slows down the reaction. The opposite behavior, i.e., fast exchange of the amino group hydrogens can be found in H/D 
experiments with molecules where the carbonyl group rotation is likely constrained (e.g., GlyGlyH ${ }^{+}$) [17], or where deuterium donor binding could be stabilized by two nitrogen atoms (e.g., $\mathrm{HisH}^{+}$) [11].

\section{Conclusions}

The results of this study lead to three main conclusions. (1) Gas-phase isotopic exchange of protonated aliphatic amino acids with deuterium donors proceeds by two independent reactions: fast exchange of only the carboxylic hydrogen and slow exchange of both the carboxylic and the amino group hydrogens. (2) The reaction energy barrier for isotopic exchange is overcome by energy gained from formation of the initial multiply hydrogen bonded reaction complex. (3) Steric hindrance from the presence of a methyl group at the $\beta-C$ atom decreases the site-specific $H / D$ exchange rate of amino group hydrogens.

\section{Acknowledgments}

The author gratefully acknowledges helpful discussions with Dr. Dunja Srzić, Dr. Leo Klasinc, and Goran Kovačević. The Ministry of Science, Education, and Sports of Republic of Croatia and Croatian Academy of Sciences and Arts Foundation supported this work.

\section{Appendix}

Table 1. (with Figure 3) The B3LYP/6-311++ $\mathrm{G}^{* *}$ energies (in $E_{\mathrm{h}}$ ) and relative stabilities of conformers (in $\mathrm{kJ} \mathrm{mol}^{-1}$ ) for $\mathrm{H} / \mathrm{D}$ exchange in $\mathrm{AlaH}^{+}$with $\mathrm{D}_{2} \mathrm{O}$

\begin{tabular}{lcr}
\hline Structure & $E$ & \multicolumn{1}{c}{$\Delta$} \\
\hline \hline AlaH $^{+}+\mathrm{D}_{2} \mathrm{O}$ & -400.670099 & 0.0 \\
HD1 & -400.699490 & -77.2 \\
TS-HD12 & -400.676754 & -17.5 \\
HD2 & -400.685966 & -41.7 \\
TS-HD23 & -400.663487 & 17.4 \\
HD3 & -400.664215 & 15.4 \\
TS-HD34 & -400.659679 & 27.4 \\
HD4 & -400.677887 & -20.4 \\
TS-HD45 & -400.665061 & 13.2 \\
HD5 & -400.684912 & -38.9 \\
TS-HD56 & -400.684449 & -37.7 \\
HD6 & -400.697164 & -71.1 \\
AlaH $_{\text {D1 }}{ }^{+}+$HDO & -400.670099 & 0.0 \\
\hline
\end{tabular}

Table 2. (with Figure 4) The B3LYP/6-311++ $\mathrm{G}^{* *}$ energies (in $E_{\mathrm{h}}$ ) and relative stabilities of conformers (in $\mathrm{kJ} \mathrm{mol}^{-1}$ ) for the $\mathrm{H} / \mathrm{D}$ exchange of $\mathrm{AlaH}^{+}$carboxylic hydrogen with $\mathrm{D}_{2} \mathrm{O}$

\begin{tabular}{llr}
\hline Structure & \multicolumn{1}{c}{$E$} & \multicolumn{1}{c}{$\Delta$} \\
\hline \hline AlaH $^{+}+\mathrm{D}_{2} \mathrm{O}$ & -400.670099 & 0.0 \\
HDC1 & -400.697164 & -71.1 \\
TS-HDC12 & -400.675448 & -14.0 \\
HDC2 & -400.691495 & -56.2 \\
AlaH $_{\mathrm{D} 1}{ }^{+}+\mathrm{HDO}$ & -400.66407 & 15.8 \\
\hline
\end{tabular}

\section{References}

1. Gard, E.; Willard, D.; Bregar, J.; Green, M. K.; Lebrilla, C. B. Site Specificity in the H/D Exchange Reaction of Gas-Phase Protonated Amino Acids with $\mathrm{CH}_{3} \mathrm{OD}$. Org. Mass Spectrom. 1993, 28, 1632-1639.

2. Gard, E.; Green, M. K.; Bregar, J.; Lebrilla, C. B. Gas-Phase Hydrogen/Deuterium Exchange as a Molecular Probe for the Interaction of Methanol and Protonated Peptides. J. Am. Soc. Mass Spectrom. 1994, 5, 623-631.

3. Campbell, S.; Rodgers, M. T.; Marzluff, E. M.; Beauchamp, J. L. Structural and Energetic Constraints on Gas-Phase Hydrogen/Deuterium Exchange Reactions of Protonated Peptides with $\mathrm{D}_{2} \mathrm{O}, \mathrm{CD}_{3} \mathrm{OD}, \mathrm{CD}_{3} \mathrm{CO}_{2} \mathrm{D}$, and $\mathrm{ND}_{3}$. J. Am. Chem. Soc. 1994, 116, 9765-9766.

4. Green, M. K.; Gard, E.; Bregar, J.; Lebrilla, C. B. H-D Exchange Kinetics of Alcohols and Protonated Peptides: Effects of Structure and Proton Affinity. J. Mass Spectrom. 1995, 30, 1103-1110.

5. Wu, J.; Gard, E.; Bregar, J.; Green, M. K.; Lebrilla, C. B. Studies of Nearest-Neighbor Interactions Between Amino Acids in Gas-Phase Protonated Peptides. J. Am. Chem. Soc. 1995, 117, 9900-9905.

6. Campbell, S.; Rodgers, M. T.; Marzluff, E. M.; Beauchamp, J. L. Deuterium Exchange as Probe of Biomolecule Structure. Fundamental Studies of Gas-Phase H/D Exchange Reactions of Protonated Glycine Oligomers with $\mathrm{D}_{2} \mathrm{O}, \mathrm{CD}_{3} \mathrm{OD}, \mathrm{CD}_{3} \mathrm{CO}_{2} \mathrm{D}$, and $\mathrm{ND}_{3}$. J. Am. Chem. Soc. 1995, 117, 12840-12854.

7. Gur, E. H.; de Koning, L. J.; Nibbering, N. M. M. The Bimolecular Hydrogen-Deuterium Exchange Behavior of Protonated Alkyl Dipeptides in the Gas Phase. J. Am. Soc. Mass Spectrom. 1995, 5, 466-477.

8. Kaltashov, I. A.; Doroshenko, V. M.; Cotter, R. J. Gas Phase Hydrogen/Deuterium Exchange Reactions of Peptide Ions in a Quadrupole Ion Trap Mass Spectrometer. Proteins: Struct. Funct. Genet. 1997, 28, 53-58.

9. Green, M. K.; Lebrilla, C. B. Ion-Molecule Reactions as Probes of Gas-Phase Structures of Peptides and Proteins. Mass Spectrom. Rev. 1997, 16, 53-71.

10. Freitas, M. A.; Hendrickson, C. L.; Emmett, M. R.; Marshall, A. G. High-Field Fourier Transform Ion Cyclotron Resonance Mass Spectrometry for Simultaneous Trapping and Gas-Phase Hydrogen/Deuterium Exchange of Peptide Ions. J. Am. Soc. Mass Spectrom. 1998, 9, 1012-1019.

11. Green, M. K.; Lebrilla, C. B. The Role of Proton-Bridged Intermediates in Promoting Hydrogen-Deuterium Exchange in Gas-Phase Protonated Diamines, Peptides and Proteins. Int. J. Mass Spectrom. Ion Processes 1998, 175, 15-26.

12. Wyttenbach, T.; Bowers, M. T. Gas Phase Conformations of Biological Molecules: The Hydrogen/Deuterium Exchange Mechanism. J. Am. Soc. Mass Spectrom. 1999, 10, 9-14.

13. He, F.; Marshall, A. G. Weighted Quasi-Newton and VariableOrder, Variable-Step Adams Algorithm for Determining SiteSpecific Reaction Rate Constants. J. Phys. Chem. A 2000, 104, 562-567.

14. Schaaff, T. G.; Stephenson, J. L., Jr.; McLuckey, S. A. Gas Phase $\mathrm{H} / \mathrm{D}$ Exchange Kinetics: DI versus $\mathrm{D}_{2} \mathrm{O}$. J. Am. Soc. Mass Spectrom. 2000, 11, 167-171.

15. Hofstadler, S. A.; Sannes-Lowery, K. A.; Griffey, R. H. Enhanced Gas-Phase Hydrogen-Deuterium Exchange of Oligonucleotide and Protein Ions Stored in an External Multipole Ion Reservoir. J. Mass Spectrom. 2000, 35, 62-70.

16. Reyzer, M. L.; Brodbelt, J. S. Gas-Phase H/D Exchange Reactions of Polyamine Complexes: $(\mathrm{M}+\mathrm{H})^{+},(\mathrm{M}+$ alkali metal $\left.^{+}\right)$, and $(\mathrm{M}+2 \mathrm{H})^{2+}$. J. Am. Soc. Mass Spectrom. 2000, 11, 711-721.

17. He, F.; Marshall, A. G.; Freitas, M. A. Assignment of GasPhase Dipeptide Amide Hydrogen Exchange Rate Constants 
by Site-Specific Substitution: GlyGly. J. Phys. Chem. B 2001, 105, 2244-2249.

18. Rožman, M.; Kazazić, S.; Klasinc, L.; Srzić, D. Kinetic of Gas-Phase Hydrogen/Deuterium Exchange and Gas-Phase Structure of Protonated Phenylalanine, Proline, Tyrosine and Tryptophan. Rapid Commun. Mass Spectrom. 2003, 17, 27692772.

19. Evans, S. E.; Lueck, N.; Marzluff, E. M. Gas Phase Hydrogen/ Deuterium Exchange of Proteins in an Ion Trap Mass Spectrometer. Int. J. Mass Spectrom. 2003, 222, 175-187.

20. Reuben, B. G.; Ritov, Y.; Geller, O.; Mc Farland, M. A.; Marshall, A. G.; Lifshitz, C. Applying a New Algorithm for Obtaining Site Specific Rate Constants for H/D Exchange of the Gas Phase Proton-Bound Arginine Dimer. Chem. Phys. Lett. 2003, 380, 88-94.

21. Lifshitz, C. A review of gas-phase H/D exchange experiments: the protonated arginine dimer and bradykinin nonapeptide systems. Int. J. Mass Spectrom. 2004, 234, 63-70.

22. Cox, H. A.; Julian, R. R.; Lee, S. W.; Beauchamp, J. L. Gas-Phase H/D Exchange of Sodiated Glycine Oligomers with $\mathrm{ND}_{3}$ : Exchange Kinetics Do Not Reflect Parent Ion Structures. J. Am. Chem. Soc. 2004, 126, 6485-6490.

23. Rožman, M., Bertoša, B., Klasinc, L., Srzić, D. Gas Phase H/D Exchange of Sodiated Amino Acids: Why Do We See Zwitterions? Unpublished.

24. Balata, B.; Basma, M.; Aviyente, V.; Zhu, C.; Lifshitz, C. Structures and Reactivity of Gaseous Glycine and its Derivatives. Int. J. Mass Spectrom. 2000, 201, 69-85.

25. M. J.; Frisch, G. W.; Trucks, H. B.; Schlegel, G. E.; Scuseria, M. A.; Robb, J. R.; Cheeseman, J. A., Montgomery, Jr.; T.; Vreven, K. N.; Kudin, J. C.; Burant, J. M.; Millam, S. S.; Iyengar, J.; Tomasi, V.; Barone, B.; Mennucci, M.; Cossi, G.; Scalmani,
N.; Rega, G. A.; Petersson, H.; Nakatsuji, M.; Hada, M.; Ehara, K.; Toyota, R.; Fukuda, J.; Hasegawa, M.; Ishida, T.; Nakajima, Y.; Honda, O.; Kitao, H.; Nakai, M.; Klene, X.; Li, J. E.; Knox, H. P.; Hratchian, J. B.; Cross, C.; Adamo, J.; Jaramillo, R.; Gomperts, R. E.; Stratmann, O.; Yazyev, A. J.; Austin, R.; Cammi, C.; Pomelli, J. W.; Ochterski, P. Y.; Ayala, K.; Morokuma, G. A.; Voth, P.; Salvador, J. J.; Dannenberg, V. G.; Zakrzewski, S.; Dapprich, A. D.; Daniels, M. C.; Strain, O.; Farkas, D. K.; Malick, A. D.; Rabuck, K.; Raghavachari, J. B.; Foresman, J. V.; Ortiz, Q.; Cui, A. G.; Baboul, S.; Clifford, J.; Cioslowski, B. B.; Stefanov, G.; Liu, A.; Liashenko, P.; Piskorz, I.; Komaromi, R. L.; Martin, D. J.; Fox, T.; Keith, M. A.; Al-Laham, C. Y.; Peng, A.; Nanayakkara, M.; Challacombe, P. M. W.; Gill, B.; Johnson, W.; Chen, M. W.; Wong, C.; Gonzalez, J. A. Pople, Gaussian 03, Revision B. 05; Gaussian, Inc.: Pittsburgh, PA, 2003.

26. Schmidt, W.; Baldridge, K. K.; Boatz, J. A.; Elbert, S. T.; Gordon, S.; Jensen, J. H.; Koseki, S.; Matsunaga, N.; Nguyen, K. A.; Su, S. J.; Windus, T. L.; Dupuis, M.; Montgomery, J. A. General Atomic and Molecular Electronic Structure System. J. Comput. Chem. 1993, 14, 1347-1363.

27. Hunter, E. P.; Lias, S. G. Evaluated Gas Phase Basicities and Proton Affinities of Molecules. (NIST Chemistry WebBook). J. Phys. Chem. Ref. Data 1998, 27, 413-656.

28. Noguera, M.; Rodrígez-Santiago, L.; Sodupe, M.; Bertran, J. Protonation of Glycine, Serine, and Cysteine. Conformations, Proton Affinities, and Intrinsic Basicities. J. Mol. Struct. Theochem. 2001, 537, 307-318.

29. Karas, M.; Glückmann, M.; Schäfer, J. Ionization in MatrixAssisted Laser Desorption/Ionization: Singly Charged Molecular Ions are the Lucky Survivors. J. Mass Spectrom. 2000, 35, $1-12$. 